\title{
Calçados e "vestuário decente e simples" como condição para Instrução Primária: uma análise sobre a obrigatoriedade escolar no Maranhão
}

\author{
Footwear and "simple decent clothing" as a condition for \\ primary education: an analysis on school compulsory in Maranhão
}

\author{
Calzado y "ropa decente y sencilla" como condición para la \\ educación primaria: un análisis sobre la obligación escolar en \\ Maranhão
}

\author{
Mariléia Santos Cruz ${ }^{1}$ \\ ORCID: $h$ ttp://orcid.org/0000-0002-2688-7653
}

\begin{abstract}
Resumo: O presente artigo aborda a desigualdade escolar favorecida pela permanência, nas leis e regulamentos da instrução pública do Maranhão, de critérios impeditivos da admissão escolar de crianças pobres sem condições de vestir roupas e calçados adequados para os padrões estabelecidos. Comparam-se medidas legais voltadas para a efetivação da obrigatoriedade escolar no período Imperial e nas primeiras três décadas da República. Analisam-se dispositivos voltados para isenção da obrigatoriedade escolar, demonstrando uma relação de exclusão social que relacionava riqueza ao direito de escolarização. Neste trabalho foram analisadas legislações da educação maranhense e jornais do período.
\end{abstract}

Palavras-chave: Ensino compulsório; Crianças pobres; Séculos XIX e XX.

Abstract: This article addresses the inequality favored by the permanence, in the laws and regulations of the public education of Maranhão, of criteria that prevent the admission of poor children without conditions to wear clothes and shoes adequate to the established standards. Legal measures aimed at enforcing school compulsory in the Imperial period and in the first three decades of the Republic are compared. Devices focused on exemption from compulsory schooling are analysed, demonstrating a relationship of social exclusion that related wealth to the right to schooling. In this work were analysed legislation of the state of Maranhão and newspapers of the period.

Keywords: Compulsory teaching; Poor children; 9th and 20th centuries.

1 Possui graduação em Pedagogia pela Universidade Federal do Maranhão (1996), mestrado em Educação pela Universidade Estadual Paulista Júlio de Mesquita Filho (2000), doutorado em Educação Escolar pela Universidade Estadual Paulista Júlio de Mesquita Filho (2008) e Pós-Doutorado na mesma instituição (20132014). Atualmente é professora Associada da Universidade Federal do Maranhão. Tem experiência na área de Educação, com ênfase em história da educação brasileira, didática, currículo e metodologias de ensino de história, atuando principalmente como pesquisadora nos seguintes temas: história da escolarização de negros no século XIX e XX, história da educação maranhense, e história da educação de Imperatriz, história da escola primária. 
Resumen: Este artículo aborda la desigualdad escolar favorecida por la permanencia, en las leyes y reglamentos de la educación pública en Maranhão, de criterios que impiden la admisión escolar de niños pobres sin condiciones para llevar ropa y calzado adecuados para las normas establecidas. Las medidas legales encaminadas a la aplicación de la escuela obligatoria se comparan en el período imperial y en las tres primeras décadas de la República. Se analizan los dispositivos destinados a la exención de las obligaciones escolares, lo que demuestra una relación de exclusión social que relacionaba la riqueza con el derecho de escolarización. En este trabajo, se analizó la legislación de la educación de Maranhão y los periódicos de la época.

Palabras clave: Enseñanza obligatoria; Niños pobres; Siglos XIX y XX.

\section{INTRODUÇÃO}

Lutero foi considerado o primeiro reformador moderno a defender a educação compulsória. Em 1526, ele colocava como obrigação das autoridades públicas a criação e a manutenção de escolas, considerando que o investimento no ensino deveria ser posto no mesmo nível de outras necessidades do país, para o bem coletivo. Em 1530, ele ampliou a ideia de compulsoriedade escolar para além do dever do poder público de abrir e manter as instituições, para a obrigação desta autoridade de "... forçar o povo a enviar seus filhos à escola" (EBY, 1970, p. 62). Para Lutero, a compulsoriedade do ensino possuía duas faces: na primeira cabia às autoridades de governo a oferta de escolas; e na segunda, os pais deveriam ser compelidos a matricular e garantir a frequência. Porém, nem sempre a obrigatoriedade escolar fez parte da pauta da modernidade. Conforme registra Eby (1970, p. 193):

A educação popular foi geralmente negligenciada na Europa católica durante os séculos XVI e XVII. Subvenções e bolsas ainda mantinham abertas, para um número restrito de meninos pobres, a entrada para o progresso na igreja, e, ocasionalmente, prelados e outras pessoas ricas mantinham meninos pobres promissores na escola ou universidade. Tais oportunidades, contudo, não produziam efeito real sobre os analfabetos e ignorância das massas; estavam abertas, em sua maioria, somente para membros pobres de famílias influentes. Não havia educação para suprir as necessidades das classes trabalhadoras.

Observando o percurso histórico da emergência da escola enquanto uma instituição voltada para o acesso ao conhecimento acumulado, de natureza intelectual, percebe-se que, desde suas origens, ela foi usada como meio de manutenção do status e reprodução do poder dos grupos de elite. A título de exemplo, vê-se que, desde a Grécia antiga, o papel de reprodução das hierarquias sociais vigorava com o aparecimento das primeiras escolas. Nesse período, o espaço se destinava a

Jovens de famílias tradicionais da antiga nobreza ou pertencentes a famílias de comerciantes enriquecidos. [...] o chamado ócio digno significava a disponibilidade de gozar do tempo livre, privilégio daqueles que não precisavam cuidar da própria 
subsistência. O que não se confunde com o "fazer nada", mas sim refere-se ao ocupar-se com as funções nobres de pensar, governar, guerrear. Não por acaso, a palavra grega para escola (scholé) significava inicialmente "o lugar do ócio" (ARANHA, 2012, p. 81, grifo da autora).

Em Atenas, quando as aprendizagens da leitura, escrita e cálculo se afirmaram como conhecimentos elementares, foram franqueadas aos pobres e aos ricos até os 13 anos, sendo a partir daí definidos destinos específicos para cada criança, conforme sua origem econômica: "pobres seguiam para os ofícios e os ricos para os ginásios" (ARANHA, 2012, p. 88).

Na Europa, no século XVI, vigorava uma escolarização diferenciada segundo as classes sociais. Enquanto os filhos das classes dirigentes dispunham de uma educação pautada na cultura e nos saberes acumulados, aos filhos dos trabalhadores estavam reservados "os elementos da religião e treinamento profissional" (EBY, 1970, p. 242).

O princípio da universalização, enquanto educação igual para todos, independentemente de gênero e classe social, foi defendido por Comenius no século XVII, por meio da Didática Magna, em 1630. Para Comenius (2002, p. 89): “... devem ser confiados à escola, não só os filhos dos ricos ou das pessoas mais importantes, mas todos em igualdade, de estirpe nobre ou comum, ricos e pobres, meninos e meninas, em todas as cidades, aldeias, povoados, vilarejos".

A educação ampla em seu conteúdo e universal na forma de atendimento das crianças e jovens se configurou como um valor atrelado à democracia. Em contraposição, sociedades aristocráticas não escondiam o incômodo despertado pelo princípio da universalização da escola. Na França, no fim do século XVII, em 1687, as ideias da aristocracia contrárias à universalidade da educação eram defendidas da seguinte forma:

\footnotetext{
Embora o conhecimento das letras seja eminentemente necessário para um país, é certo que não devem ser ensinadas a todos. Assim como um corpo que tivesse muitos olhos por todos os lados seria monstruoso, da mesma forma o seria o Estado se todos os seus cidadãos fossem eruditos; menos obediência seria encontrada, e orgulho e presunção seriam mais comuns [...]. Se as letras fossem profanadas para todos os tipos de espírito ver-se-iam mais pessoas prontas a levantar dúvidas do que a resolvê-las, e muitas estariam mais prontas a opor-se à verdade do que a defendê-la. É por esta razão que a política exige em um Estado bem regulamentado mais mestres de artes mecânicas que de artes liberais para ensinar as letras (apud EBY, 1970, p. 245).
}

Os princípios da obrigatoriedade e da universalização se tornaram importantes valores no campo da pedagogia, ultrapassando os limites temporais e teóricos da modernidade. Mesmo assim, a história da educação registra uma tensão em torno da concretização destes valores. No Brasil, a compulsoriedade do ensino tornou-se um tema de constante debate durante o século XIX, até as primeiras décadas do século XX. A Constituição de 1824 representou a diretriz primeira que, colocada acima das regulamentações provinciais, 
imprimiu o princípio da obrigatoriedade e gratuidade da instrução primária a todos os cidadãos (CONSTITUIÇÃO..., 1824, art. 179). Diante do estabelecido pela Constituição de 1824, cada província deveria alinhar a política local com a nacional, sobretudo a partir do ato adicional de 1834.

Acreditava-se que só por meio do ensino obrigatório a nação poderia incorporar a cultura da escolarização, na medida que as famílias ficavam proibidas de descuidar da matrícula e da frequência dos menores em idade escolar. A escolarização representava uma condição para elevação nacional, para a cidadania nos moldes liberais, e uma condição para alcançar o desenvolvimento social e econômico. Entre os problemas listados como impeditivos da instituição da compulsoriedade da instrução primária, segundo se constata em Brito e Vinagre (2018), estava a questão do atendimento da demanda de crianças em idade escolar em instituições públicas. Obrigar as famílias à matrícula da criança, impondo pagamento de multas aos descumpridores do dispositivo, só fazia sentido se houvesse difusão ampla do ensino.

Tornar obrigatória a matrícula para todas as crianças na idade escolar, embora no Brasil tenha sido uma ação inspirada na compulsoriedade da vacina (GONDRA, 2018), não foi algo posto em prática da mesma forma. Enquanto o processo de imunização foi financiado pelo poder público, cabendo às famílias o dever de entregarem as crianças para serem vacinadas, no caso da compulsoriedade da instrução pública, o Estado estabeleceu a cobrança de multas para as famílias que negligenciassem o dever de matricular suas crianças, mas não garantiu a abertura de escolas suficientes para toda a demanda. Sendo assim, a obrigatoriedade escolar estabelecida no Brasil estava mais para obrigar os pais a promoverem o ensino, do que para o dever do poder público de ofertar a escolarização, conforme constatou Vidal (2013), com base em análises sobre a obrigatoriedade em várias províncias, no século XIX. Vidal (2013) afirma que a interferência do Estado sobre a autoridade dos pais na promoção da frequência escolar previa o ensino compulsório e não a escola compulsória, já que o foco central não era a matrícula escolar, mas o ensino, que poderia se concretizar até mesmo na própria casa da família.

Diante das dificuldades orçamentárias para que o próprio Estado assumisse a função de promoção escolar, duas poderiam ser as atitudes tomadas pelo poder público, visando à concretização de dispositivos voltados para a compulsoriedade da instrução: a primeira saída seria para os mais pobres, e a segunda, para as famílias que pudessem pagar pela escolarização. Como os mais pobres não reuniam condições para serem obrigados ao pagamento de multas, fazia-se necessário isentá-los ou provê-los materialmente. Por outro lado, se o Governo não investia na ampla difusão da instrução, tornava-se necessário que, junto com a obrigatoriedade escolar, fosse fortalecido o princípio da liberdade de ensino, por meio do qual daria espaço para existência de escolas particulares, a quem pudesse pagar (BRITO; VINAGRE, 2018). 
Observa-se que a obrigatoriedade, no século XIX, se torna mais um dispositivo de exclusão escolar do que um meio de promover a expansão dos conhecimentos clássicos e a efetiva consolidação da cultura da escolarização, na medida em que a matrícula compulsória só serviria para quem tivesse condições econômicas. Por outro lado, com a instituição da República, o quadro de exclusão não se modifica de imediato.

Em estudo sobre desigualdade escolar respaldado em fontes sobre a instrução pública de Minas Gerais, Veiga (2016, p. 300) salienta que "mecanismos internos e cotidianos de exclusão há muito estiveram presentes na história da educação brasileira", de modo que com a instauração da República, ao se estabelecer a organização e modernização do sistema de ensino, a escola pública se especializou como instituição seletiva, distanciando-se dos setores mais empobrecidos.

A coeducação, a obrigatoriedade escolar e a universalização do ensino (escola única) foram valores pedagógicos da modernidade, difundidos de forma mais ampla no Brasil pela Escola Nova. Os intelectuais escolanovistas promoveram a circulação de ideias que foram importantes para formação e organização do sistema nacional de educação brasileiro. Para os defensores do Manifesto de 1932, a escola representava uma instituição colocada acima das classes, devendo assumir a função social de oferecer as condições para fazer desenvolver as potências individuais, os talentos de cada um, independentemente de cor, gênero e status econômico. Seu papel seria atuar junto às novas gerações, selecionando as melhores cabeças para serem encaminhadas a níveis mais elevados de conhecimento, qualificando uma elite preparada para dirigir o país (O MANIFESTO [...], 1932).

É inegável a influência da Escola Nova em todo o Brasil, fazendo-se presente, tanto no espírito dos trechos das reformas nos estados, quanto funcionando como procedimento padrão do cotidiano da formação docente, constando nas práticas de ensino consideradas inovadoras e conduzindo as formas de organização escolar. Contudo, os preceitos da escola única, acessível a todas as classes, não passou de uma ilusão, permanecendo um sistema de ensino composto por variados tipos escolares e pouco acessado pelos mais pobres (CRUZ, 2019a).

No Maranhão, verifica-se que esse processo de exclusão é significativo tanto no período Imperial quanto no Republicano, sendo a ausência de calçados e o tipo de vestuário os elementos mais identitários da pobreza dos alunos utilizados nos textos de documentos da legislação de ensino. A aparência de pobre era considerada inapropriada para o acesso ao refinamento cultural prometido pela escolarização.

Neste texto, abordamos a desigualdade de oportunidade escolar favorecida pela permanência, nas leis e regulamentos da instrução pública do Maranhão, de critérios impeditivos da admissão escolar de crianças sem condições de vestir roupas e calçados adequados, conforme padrões superiores à condição de pobreza da grande parte das crianças maranhenses. Compara-se as medidas legais voltadas para a efetivação da obrigatoriedade escolar no período imperial e nas primeiras três décadas da República. As fontes de 
pesquisa utilizadas no presente estudo consistiram nas legislações que regulamentaram a educação escolar maranhense, no período do século XIX, até as três primeiras décadas da República, e a imprensa maranhense.

\section{A OBRIGATORIEDADE ESCOLAR PARA CRIANÇAS POBRES MARANHENSES NO SÉCULO XIX}

Logo depois do ato adicional de 1834, com a autonomia das províncias, prepararam-se as condições para a existência de um conjunto de leis no nível regional, possibilitando que esforços internos ao espaço provincial delineassem uma trajetória histórica específica da educação.

Embora a organização da Instrução Pública maranhense tenha como marco o ano de 1838, com a criação da escola Normal (Lei n. ${ }^{\circ} 76$, de 24 de julho de 1838) e do Liceu Maranhense (Lei n. ${ }^{\circ} 77$, de 24 de julho de 1838) será a partir de 1841, que as atenções e os esforços foram articulados visando reformá-la. A consequência desse movimento é a Lei n. ${ }^{\circ} 115$, de 1 de setembro de $1841^{2}$ (MARANHÃO, 1843), e o Regulamento de 3 de outubro. Na primeira, aprova-se o estatuto do Liceu e outras providências, entre as quais o artigo $9 .^{\circ}$ dispõe sobre a liberdade de ensino; e a segunda, trata-se do Regulamento de 3 de outubro, que versa sobre o cargo de Inspetor da Instrução Pública. Viveiros (1953, p.15) descreve da seguinte forma o Regulamento de 3 de outubro de 1841:

\footnotetext{
Por este regulamento_o primeiro que tivemos_eram atribuições do inspetor: fiscalizar e inspecionar por si e seus delegados todas as escolas da província, regular e dirigir o sistema de método da prática de ensino, fazer os regulamentos internos das escolas, dar os professores os esclarecimentos necessários para o desempenho de suas obrigações, visitar mensalmente as escolas da Capital, vigiar sobre o procedimento dos professores particulares, servir de intermediário entre o Governo e os professores, e fazer de seis em seis meses, relatórios do estado da Instrução Pública da Província.
}

Viveiros acrescenta que o ano de 1841 foi fecundo para a educação pública da província, já que foi um período especial para o estabelecimento das regras para sua organização, além de ter sido o ano de abertura de importantes escolas particulares e a fundação da Casa dos Educando Artífices (VIVEIROS, 1953).

A Casa dos Educandos Artífices foi criada em virtude da Lei $n .^{\circ} 105$, de 23 de agosto de 1841, visando à educação profissional de "[...] meninos pobres e desvalidos de toda a província, que o mesmo Presidente julgar aptos para aprenderem ofícios mecânicos, tendo com tudo preferência os expostos da Santa Casa de Misericórdia" (REGULAMENTO [...],

2 A Lei n. $^{\circ} 115$ não se restringe apenas à instrução pública primária, dando destaque para os estatutos do Liceu. 
2009a, p. 320). Nesta instituição, pretendia-se atender crianças pobres e desvalidas, menores de 18 anos e maiores de 12, desde que não estivessem na condição de escravizados e que fossem vacinados (REGULAMENTO [...], 2009b).

Em 1849, entra em cena a da Lei n. ${ }^{\circ} 267$, de 17 de dezembro, voltada para regulamentar a Instrução Pública do Maranhão, abrangendo a organização geral do sistema. Esta lei disciplinou questões relativas ao ensino de primeiras letras, a exemplo dos métodos, gratificações dos professores, exames para provimento das cadeiras, aposentadoria; e sobre o ensino secundário do Liceu Maranhense (MARANHÃO, 1849). Em 1850, uma nova lei, de número $282,{ }^{3}$ de 28 de novembro, altera a instrução pública maranhense. A tônica principal da nova reforma foi a extinção de cadeiras, o que prejudicava diretamente alguns opositores, funcionando como um meio de retaliação pessoal.

Em 1855, entrou em vigor a mais longeva legislação usada para regulamentar a instrução no Maranhão, durante o século XIX, que foi o Regulamento da Instrução Pública de 2 de fevereiro. Tal afirmativa tem por base o fato de que, embora tenha sido alterada, reformulada ou substituída por sucessivas vezes, foi a principal legislação que respaldou as deliberações sobre educação na província, sendo definitivamente substituída apenas em $1874 .^{4}$

No artigo 36, do Regulamento da Instrução Pública, de 2 de fevereiro de 1855, estava estabelecida a multa $10 \$ 000$ réis aos "pais, tutores, curadores e protetores, que tivessem em sua companhia meninos maiores de 7 anos sem impedimento físico ou moral, que não lhes derem o ensino, ao menos do primeiro grau" (REGULAMENTO..., 2009c, p. 390). Neste mesmo documento consta que as crianças muito pobres, sem condições de se apresentarem bem vestidas, deveriam ser objeto de assistência do Estado. Segundo o artigo 90 do Regulamento de 1855, "Os delegados da instrução pública darão parte ao inspetor da existência na localidade de meninos manifestadamente indigentes, a quem não possam os pais, tutores ou curadores fornecer vestuário decente e simples para frequentar as escolas (REGULAMENTO [...], 2009c, p. 394, grifo nosso).

Sendo assim, ficou previsto que as autoridades deveriam fornecer o vestuário necessário, identificando também os que vivessem em mendicância. Para estas últimas crianças, devidamente confirmada a mendicidade, estava prevista a instrução por conta do governo, o que poderia ocorrer por meio de pagamento mensal a párocos, professores contratados para essa finalidade ou encaminhados para escolas públicas da capital (art. 91), para serem

3 Silva (2018) considera essa lei como resultante das disputas e alternância de poder entre as forças políticas da elite maranhense.

4 Em 1861, por meio da Lei n. ${ }^{\circ} 611$ de 23 de setembro, foi alterada pela primeira vez o regulamento de 1855. Em 1863, com a Lei n. ${ }^{\circ} 672$, de 11 de julho, revogava-se a Lei n. ${ }^{\circ} 611$, restabelecendo-se o retorno ao Regulamento de 1855 , com algumas alterações. No ano seguinte, em 1864, por meio da Lei n. $^{\circ} 719$, de 18 de julho, revoga-se a lei de 1863 (n. ${ }^{\circ} 672$ ), promovendo o retorno quase integral ao Regulamento de 2 de fevereiro de 1855. Em 1866, outra lei, a de n. ${ }^{\circ} 781$, de 11 de julho, aprova o regulamento de 7 de abril do mesmo ano, com alterações, e em 1868, a Lei n. ${ }^{\circ} 846$, de 13 de julho, revoga a Lei n. ${ }^{\circ} 781$ e o regulamento de 7 de abril, fazendo entrar em inteiro vigor com força de lei o regulamento de 2 de fevereiro de 1855 (SILVA, 2018). 
instruídos nos conhecimentos rudimentares da escola primária. Posteriormente, meninos que demonstrassem capacidade para os "estudos superiores" seriam encaminhados para a Escola Pedro II, ou até para a Europa, enquanto os de menor inclinação para o estudo, deveriam ser encaminhados para aprendizagem de ofícios (Art. 92). ${ }^{5}$

Outra escola, criada pelo Governo com o objetivo de “... amparar as meninas órfãs que forem desvalidas e as expostas da Santa Casa de Misericórdia [...]" foi o Asilo de Santa Teresa, em 1855. Diferenciava-se dos recolhimentos, porque não tinha finalidade de formação religiosa e, enquanto congênere da Casa dos Educandos Artífices, tinha uma natureza profissionalizante, voltada para “... educá-las por maneira que possam ser empregadas com vantagem no serviço doméstico" (REGULAMENTO [...], 2009d, p. 364). Neste documento, não consta nenhum impedimento à matrícula, omitindo-se até o veto de crianças escravizadas; algo comum tanto no Regulamento da Instrução Pública de 2 de fevereiro, quando no Regulamento da Casa dos Educandos Artífices, do mesmo ano.

A Lei $n .^{\circ} 672$, de 11 de julho de 1863, é a primeira que retorna ao regulamento de 1855, após a sua revogação pela Lei n. 611 de 1861. Dentre as alterações do Regulamento de 1855 , no artigo $2 .^{\circ}$, da Lei n. ${ }^{\circ} 672$, há o reforço do dispositivo de obrigatoriedade escolar do ensino primário. No artigo $3 .^{\circ}$, determina-se punição com prisão aos pais, tutores ou curadores sem condições de pagar pela multa no caso de negligenciarem à matrícula das crianças em idade escolar (SILVA, 2018). Essa alteração, torna sem efeito o que estava estabelecido em 1855, quando se definiu perdão de multa, por questão de pobreza, aos responsáveis descumpridores do dispositivo de obrigatoriedade.

Outro importante Regulamento da Instrução Pública do Maranhão, da segunda metade do século XIX, foi o de 1874. Neste documento, além de mantida a diferenciação do currículo conforme a localidade, consta o dispositivo de obrigatoriedade escolar, no artigo 6. ${ }^{\circ}$ Para garantir a obrigatoriedade, mais uma vez recorre-se às multas aos responsáveis pelas crianças (pais, tutores, curadores e protetores) maiores de 7 anos, que não "Ihes derem ensino primário" (REGULAMENTO [...], 2009e, p. 400).

O Regulamento de 1874 isenta da obrigatoriedade escolar os deficientes físicos (art. $6^{\circ}{ }^{\circ}$ ), ao mesmo tempo em que torna livre da penalidade com multa os responsáveis pelos maiores de 7 anos, "que forem notoriamente indigentes" (art. 8. ${ }^{\circ}$ ). Posteriormente, no Regimento Interno para as Escolas Públicas de primeiras letras de 1877, baixado em conformidade com o artigo 82, do Regulamento de 1874, destaca-se, mais uma vez, o caráter impeditivo da matrícula aos não vacinados e portadores de doença contagiosas (REGIMENTO [...], 2009, p. 417), que no documento de 1855 já constavam como impedidos à matrícula e que foram ignorados no Regulamento de 1874.

5 A reforma Couto Ferraz, posta em prática na Corte, desde 1854, foi a inspiração para a definição dos procedimentos direcionados para garantir a obrigatoriedade escolar às crianças indigentes. Nos artigos $62 \mathrm{e}$ 63, textualmente, quase todo conteúdo reproduzido no regulamento do Maranhão, estão contemplados (Cf. GONDRA, 2018). 
De um documento para o outro, observa-se que o estabelecimento da compulsoriedade da instrução, que deveria ser compreendido como uma ampliação da oportunidade escolar, funcionava como restrição ao acesso. Percebe-se que enquanto a reforma de 1855 não isentou os pobres malvestidos e mendigos da obrigatoriedade, colocando-os sob a responsabilidade do Estado, o documento de 1874 confere liberdade aos pobres de permanecerem sem instrução. Na prática, ao menos em termos legais, de uma lei para a outra, houve uma diminuição das oportunidades escolares das crianças indigentes, já que deixam de ser uma responsabilidade do governo, e seus responsáveis se tornam isentos da penalidade com multa.

Em conformidade com Chervel (1990), entendemos que as leis e regulamentos, enquanto documentos legais, embora pareçam sancionar oficialmente uma realidade, não devem ser concebidos como os instituidores da realidade, pois além da intencionalidade expressa nessas fontes, deve-se “... tomar consciência de que uma estipulação oficial [...] visa mais frequentemente, mesmo se ela é expressa em termos positivos, corrigir um estado de coisas, modificar ou suprimir certas práticas, do que sancionar oficialmente uma realidade" (CHERVEL, 1990, p. 190).

As leis do período estavam mais para impedir ou dificultar o acesso escolar das crianças pobres, doentes e deficientes do que para incluí-las, conforme se espera quando o tema da obrigatoriedade escolar é colocado em pauta. Desse modo, pode-se constatar que a educação escolar não era vista como uma necessidade social para o bem comum, mas como um privilégio de grupos economicamente bem-sucedidos. Enquanto privilégio, o acesso dos pobres à instrução pública de forma ampla poderia pôr em risco posições consagradas de gerência, sendo necessário conter as possibilidades dos grupos subjugados, limitando ou impedindo o acesso. Mesmo para os que estavam dentro dos critérios para serem obrigados à matrícula, o dispositivo da compulsoriedade torna-se sem efeito e até inexistente na Província, conforme atesta Castro (2013), com base em análises de relatórios de inspetores da instrução pública maranhense. O autor demonstra que houve "frouxidão" em fazer valer a penalidade com aplicação de multas aos responsáveis descumpridores dos dispositivos de obrigatoriedade.

\section{OPORTUNIDADE ESCOLAR DA CRIANÇA POBRE NO MARANHÃO IMPERIAL}

O primeiro censo realizado no Brasil, em 1872, revela que o Maranhão possuía uma população geral na ordem de 359.040 pessoas, sendo que 78,95\% tinham o status jurídico de livres, enquanto 21,05\% correspondiam sujeitos em condição escrava (RECENSEAMENTO [...], 1874a).

Era de 13.583 o número de pessoas livres com idade entre 6 a 15 anos que se encontravam matriculadas nas escolas do Maranhão, contra 57.709 que não tinham acesso à instrução. Ao contrário do grande número de crianças fora da escola, destaca-se como outra característica do período a presença de um ínfimo número de "professores e homens de letras", que não passavam de 260 em toda a província. O analfabetismo também se demonstrava 
assustador, atingindo a cifra de 215.522 pessoas livres, o que equivalia a praticamente dois terços da população geral, sem considerar as que viviam em condição escravizada, dentre as quais, apenas 72 sabiam ler e escrever (RECENSEAMENTO [...], 1874b).

Do ponto de vista religioso, a província maranhense possuía seu território organizado em 53 paróquias, distribuídas em 37 municípios (MARQUES, 1970, p. 286). Assim, dessas 53 paróquias, 7 estavam concentradas na ilha de São Luís: Nossa Senhora da Victória da Catedral, Nossa Senhora da Conceição, São João Batista, São Joaquim do Bacanga, São João Batista de Vinhais, Nossa Senhora da Luz do Paço do Lumiar e São José do Lugar dos Índios.

Considerando o universo total de 53 paróquias, observa-se no recenseamento de 1872 que a cobertura escolar era muito restrita, já que em apenas duas (a de Nossa Senhora da Victória e a de São João Batista) o número de crianças em idade de escolarização, que se encontrava com vínculo escolar, aparece como superior ao das que não frequentavam escola (985 e 652, que frequentavam escola, contra 553 e 448, que não frequentavam, respectivamente) (RECENSEAMENTO [...], 1874a). Em todas as demais paróquias, a discrepância era alarmante, conforme pode-se observar em algumas delas, descritas abaixo:

Quadro 1 - Demonstrativo do número de indivíduos em idade escolar (6 a 15 anos) que frequentam escola, analfabetismo e número de "professores e homens de letras" em $12^{6}$ paróquias do Maranhão, no ano de

1872.

\begin{tabular}{|l|c|c|c|c|}
\hline \multicolumn{1}{|c|}{ Paróquia } & Frequenta & $\begin{array}{c}\text { Não } \\
\text { frequenta }\end{array}$ & $\begin{array}{c}\text { Professores } \\
\text { e homens } \\
\text { de letras }\end{array}$ & Analfabetos \\
\hline N. Sra. da Conceição & 665 & 778 & 27 & 6.477 \\
\hline S. Joaquim do Bacanga & 80 & 523 & 07 & 1.210 \\
\hline S. João Batista de Vinhaes & 52 & 281 & 17 & 805 \\
\hline N. Sra. da L. do P. do Lumiar & 18 & 434 & 01 & 2801 \\
\hline São José dos índios & 8 & 234 & 02 & 805 \\
\hline São Mathias de Alcântara & 417 & 798 & 08 & 6.838 \\
\hline São João de Côrtes & 24 & 223 & 01 & 1.008 \\
\hline Santo Antônio e Almas & 195 & 1142 & 03 & 6.133 \\
\hline São Bento dos Perizes & 629 & 1321 & 07 & 9.172 \\
\hline São José de Guimarães & 309 & 1502 & 09 & 12.448 \\
\hline S. João Batista do Cururupu & 405 & 1802 & 02 & 10.462 \\
\hline S. F. X. do Tury-Ássú & 228 & 1374 & 03 & 4.689 \\
\hline
\end{tabular}

Fonte: Elaborado pela autora com base no Recenseamento de 1872 (RECENSEAMENTO [...], 1874a).

6 As 12 paróquias discriminadas no quadro foram escolhidas aleatoriamente, respeitando-se, principalmente, a ordem que aparecem no Recenseamento de 1872, dentre as 53 que faziam parte da Província do Maranhão. Das 53 paróquias, apenas duas apresentam número superior de crianças e adolescentes que frequentam escola. Em todas as 51 paróquias o número de crianças e adolescentes que frequentavam escola é muito inferior ao número das que não frequentavam. 
A Paróquia de Nossa Senhora da Victória tratava-se da região mais urbana da Província, onde se originou o Maranhão, fundado pelos franceses em 1612, e depois retomado pelos portugueses, em 1614. Esta Paróquia, considerando a classificação da população pelas atividades profissionais, destacava-se como o local com maior número de professores e profissionais das letras (35), além de uma população alfabetizada superior ao identificado nas outras. Economicamente falando, encontravam-se nesta região as principais famílias da Província, a exemplo de empregados públicos, médicos, artistas, farmacêuticos, capitalistas proprietários de armazém, comerciantes e outros. Esta parcela da população detentora de capital cultural e/ou material, concentrava-se nas Paróquias centrais da capital, incluindo-se aí, além da de Nossa Senhora da Victória, a de Nossa Senhora da Conceição e a de São João Batista. Outras Paróquias que faziam parte da capital da província, localizadas em zonas mais periféricas, apresentavam menor concentração de abastados e número superior de população analfabeta (São Joaquim do Bacanga, São João Batista de Vinhais, Nossa Senhora da Luz do Paço do Lumiar e São José do Lugar dos Índios).

Nesse mesmo ano de 1872, registra-se a existência de 117 cadeiras públicas de instrução primária, 23 escolas particulares deste mesmo nível, além de 1 escola de ensino secundário pública e 11 colégios particulares. Todo esse universo perfazia um total geral de 152 escolas no Maranhão (MARANHÃO, 1872, p. 21) para atender a população em idade escolar, com o elevado número de 71.292 crianças e jovens. Desse modo, constata-se que a Província possuía uma população infanto-juvenil majoritariamente desprovida do acesso escolar, o que provavelmente coincidia com a condição de pobreza da região.

Afirmar que crianças pobres do Maranhão oitocentista não tiveram acesso à instrução pública parece precipitado, já que a população se constituía massivamente de camadas sociais empobrecidas. No entanto, observa-se que a instrução pública no século XIX não tinha como público alvo essas crianças, tendo em vista que, conforme se percebe na análise das fontes do período, dava-se muita importância ao vestuário. Parecia crença generalizada que a escolarização estava para a condição econômica, como o trabalho manual estava para os pobres. Embora não se afirmasse literalmente que as crianças pobres estavam vetadas da escolarização, por causa da pobreza, estava explícito que a escola deveria ser um espaço ocupado por quem dispunha de boa roupa e bons calçados. Ficava evidente que uma condição indispensável para escolarização do grupo destituído de riqueza era que ao menos não apresentasse a aparência de malvestido ou descalço. Apesar das escolas serem poucas, e fossem privilegiados os sujeitos que se encontravam em melhores condições econômicas, a aceitação de pobres estava condicionada ao fornecimento do vestuário pelo governo ou por terceiros.

Por certo que, apesar da escola do período ter sido pensada como uma instituição que deveria ser frequentada por crianças e jovens materialmente bem-sucedidos, em grande parte delas, situadas em toda a província, estavam crianças que contrariavam o perfil 
idealizado de "discípulo", 7 já que a escola não era considerada como um local onde os pobres tinham a liberdade de comparecer segundo o seu aspecto peculiar de desprovidos materialmente. A pobreza das crianças era identificada como obstáculo para o sucesso do sistema, conforme pode-se constatar no registro do Inspetor da Instrução Pública de 1861, transcrito a seguir:

[...] Este número de alunos examinados ainda não está em relação com os dos matriculados, o que atribuo a três causa:

$1^{\circ}$. A pobreza da maior parte dos alunos que abandonam as escolas para se empregarem em trabalhos de que Ihes renda proveito imediato;

$2^{\circ}$. A falta de livros indispensáveis que a província não fornece os alunos pobres;

$3^{\circ}$. Finamente a negligência de algum professor que não cumprem seus deveres.

[...] a falta de compêndios adotados para serem distribuídos pelos alunos pobres é também um grande obstáculo ao ensino. A maior parte dos professores ensinam pelos compêndios que lhes apresentam os alunos, que não estão em circunstâncias de comprarem os adotados. [...]. A assembleia provincial, talvez às vistas dos minguados recursos da província, ainda não decretou fundos para compra de compêndios para os alunos pobres (RELATÓRIO..., 1861, p. 1-2).

As constantes queixas sobre a infrequência dos alunos por dificuldades financeiras, a limitada ocorrência de exames, denunciando a fraca qualidade do ensino, além das queixas sobre a impossibilidade de ministrar o ensino com eficiência por falta de livros, são elementos que caracterizam o contexto da realidade pobre da província. A escola oferecida pelo poder público era sempre criticada por não apresentar os resultados esperados, já que o contexto real impedia a concretização de uma escola pública eficiente.

Enquanto não havia a definição de recurso provincial especificamente destinado ao socorro dos escolares pobres das escolas oficiais, outras formas de socorro vigoravam à época, como medidas paralelas, como se as crianças pobres fossem a exceção da província. Não era incomum a ocorrência de doações de particulares, existência de instituições filantrópicas voltadas para a instrução de alunos pobres, manutenção, pelo poder público, de determinado número de alunos pobres em escolas particulares, incluindo as de caráter religioso.

Uma dessas situações é a referente à subvenção semestral concedida pelo governo provincial para a alimentação, calçados e vestuário de 14 alunos pobres mantidos no Seminário de Santo Antônio e no Pequeno Seminário de Nossa Senhora das Mercês (PUBLICADOR MARANHENSE, 1870, p. 2). O Seminário de Santo Antônio destinava-se a aspirantes ao sacerdócio, e o de Nossa Senhora das Mercês voltava-se para a instrução nos estudos do primário e do secundário (MARQUES, 2008, p. 855).

7 Termo usado na época como sinônimo de aluno. 
A Casa dos Educandos Artífices, criada em 1841, era oficialmente a escola pública destinada aos meninos pobres e desvalidos, e ali, além da formação nas primeiras letras, e dos ofícios mecânicos, o Governo fornecia alimentação e vestuário, conforme descrito no Regulamento de 1841:

A Casa garante igualmente alimentos, vestimentas e tratamento nas moléstias. [...] Art. $6 .^{\circ}$. A vestimenta constará anualmente enquanto diferente solução não houver, de três jaques de brim, três calças ditas, três camisas de algodão, um par de suspensórios, um boné de formatura, um dito para o serviço ordinário, uma gravata, seis pares de sapatos. Os alimentos serão ministrados a arbítrio do Diretor, pela forma abaixo prescrita (REGULAMENTO [...], 2009a, p.320).

Outra importante iniciativa em favor dos alunos pobres foi a criação, em 11 de abril de 1877, da Sociedade Maranhense Protetora dos Alunos Pobres, com o objetivo de promover o fornecimento de vestuário e calçado aos meninos de ambos os sexos visando garantir a frequência nas escolas primárias da comarca da capital (GOVERNO [...], 1877). Esta sociedade possuía congêneres na Comarca do Baixo-Mearim, no interior da Província, denominada Sociedade Beneficente Auxiliadora da Instrução Pública e em Guimarães, denominada Sociedade Propagadora da Instrução Primária em Guimarães (PUBLICADOR MARANHENSE, 1877, p.3).

O auxílio prestado às crianças pobres deveria ser financiado por meio de recursos originados de oferta mensal dos seus sócios e doações de valores de outros beneméritos, comprometidos com a instrução pública, conforme consta no Diário do Maranhão de 1877 (p. 2), quando Joaquim Mariano Pereira Jorge, escrivão do termo de Cururupu, doou 119\$ 000 em benefício desta sociedade.

Dado o elevado índice de crianças pobres em idade de estudar fora dos estabelecimentos escolares no Maranhão, resta-nos questionar quais seriam os critérios usados para definir quem seria escolhido para usufruir do benefício das vagas em escolas particulares financiadas pelo governo ou com a proteção das sociedades voltadas para o socorro dos alunos pobres?

Não identificamos documentação específica do poder público, que conceituasse pobreza, ou que descrevesse critérios para seleção dos alunos pobres socorridos. Contudo, o artigo 26 do Estatuto da Sociedade Maranhense Protetora dos Alunos Pobres deixa claro quais deveriam ser as crianças preferenciais para a proteção que ofereciam. Para eles, esses alunos deveriam ser: "os órfãos principalmente de funcionários públicos, filhos de voluntários da pátria e de viúvas honestas" (GOVERNO [...], 1877, p. 1).

A orfandade considerada no período era a de pai, o que só se concretizava com a efetivação do casamento legítimo. A criança órfã deveria ser filho de funcionário público e de ex-combatentes da guerra do Paraguai, o que nos leva a supor que as crianças beneficiadas se encontravam em um grupo com organização familiar privilegiada, em relação à 
grande maioria. Tal aspecto restringia a assistência ao segmento de pessoas do meio próximo dos responsáveis pela ação caritativa, sendo impensada a proteção ao grande universo de crianças populares.

Outra questão interessante sobre a temática da ação caritativa em favor dos alunos pobres diz respeito ao principal objeto do atendimento da Sociedade, que consistia no fornecimento da indumentária considerada adequada para a frequência escolar dos primários. Conforme descrito no Estatuto da Sociedade Maranhense Protetora dos Alunos Pobres, "A cada aluno pobre se distribuirá anualmente três calças, três camisas e duas jaquetas de fazenda forte e econômica, três pares de sapato e um chapéu; e a cada menina, três vestidos de chita, quatro camisas e três pares de sapato" (GOVERNO [...], 1877, p. 1). Ao que parece, garantir a vestimenta adequada para a frequência escolar estava acima da própria garantia de utensílios como livro, papel, pena e tinta, os quais nos parece consistirem em objetos mais indispensáveis para o estudo do que roupas e calçados. Em apenas uma parte do Estatuto da referida Sociedade, no artigo 32, se faz menção à distribuição de materiais especificamente destinados à atividade de estudo, porém, a referência se trata de uma possibilidade de socorro a meninos do interior da Província. Registra-se que: "A sociedade estenderá seu benefício aos meninos do interior da província, quando o permitirem seus fundos, e em tal caso o auxílio, fornecendo livro, papel, pena e tinta, e ainda promoverá a abertura de aulas para a instrução primária." (GOVERNO [...], 1877, p. 1). Percebe-se que tanto a questão do auxílio aos estudantes do interior com utensílios, quanto a promoção da abertura de escolas fora da capital, constam como iniciativas secundárias, para o caso de sobra de recursos. A demanda mais relevante em relação ao atendimento dos pequenos pobres concentrava-se no fornecimento do vestuário.

\section{A REPÚBLICA E A PERMANÊNCIA DA DESIGUALDADE DE OPORTUNIDADE ESCOLAR NOS REGULAMENTOS DO ENSINO PRIMÁRIO NO MARANHÃO}

Desde 1890 até 1900, a história da educação evidencia um intenso movimento em torno da organização do sistema de educação do Estado do Maranhão, o que se fez visível na extensão do conjunto de leis para regular a educação primária, nos primeiros anos da República. Embora as várias reformas do período se contraponham em alguns aspectos, há que se destacar entre elas uma semelhança, que é o registro de critérios impeditivos para um amplo acesso à escola primária ou a determinação da diferenciação curricular em conformidade com a localização da escola, intensificando a ideia de educação como privilégio.

A primeira reforma republicana maranhense ocorreu em 1890, por meio do decreto n. ${ }^{\circ} 21$, de 15 de abril. Nesta reforma, não constam dispositivos sobre obrigatoriedade de ensino e o primário era considerado facultativo, devendo ser oferecido em escolas com diferenças curriculares de três tipos: escolas de $1 .^{\circ}, 2^{\circ}$ e $3 .^{\circ}$ graus, definidas conforme a 
sua localização em povoados, vilas e cidades. Para cada uma, em ordem crescente, havia a definição dos conteúdos específicos de ensino, sendo o currículo rudimentar destinado para a escola do povoado (MARANHÃO, 1893).

Embora a obrigatoriedade tenha sido estabelecida no Maranhão, desde a segunda metade do século XIX, dados relativos à compulsoriedade da Instrução Pública na história da educação maranhense confirmam o observado em outras localidades do Brasil conforme apontado por Vidal (2013, p.14):

Não é possível supor, entretanto, que uma vez promulgada, a obrigatoriedade de ensino foi instaurada nas respectivas Províncias. Ao contrário [...], em geral, leis posteriores reiteram ou excluíram o dispositivo legal por motivos vários, dentre eles o não cumprimento da legislação, a falta de meios para inspecionar as escolas ou mesmo a pobreza ou incúria das famílias.

No ano seguinte, em 1891, novo decreto é editado, visando reorganizar a instrução primária. Trata-se do Decreto n. ${ }^{\circ}$ 94, de 1 de setembro de 1891 . Ao contrário do anterior, ficou garantida a liberdade, a laicidade, a gratuidade e a obrigatoriedade do ensino primário (art. $2^{\circ}$, Decreto n. ${ }^{\circ} 94$ ), embora tenha se mantido a diferenciação curricular em conformidade com a localização da escola. Conforme esse decreto, a educação primária é de responsabilidade do município, podendo o estado criar e manter escolas em todos os municípios com exceção da capital (arts. 40 e 41) (GOVERNO [...], 1891).

Inspirada na reforma Benjamin Constant, ${ }^{8}$ observa-se a ausência de mecanismos impeditivos à matrícula de crianças pobres, permanecendo apenas a restrição de matrícula de crianças não vacinadas e com doenças contagiosas (GOVERNO..., 1891, art. 67). Embora o decreto de 1891 tenha se inspirado na Reforma Benjamin Constant, e por isso tenha recebido influências liberais em consonância com o contexto de fortalecimento da República, esta reforma não chegou a ser implantada devido aos problemas e embates entre grupos políticos nas disputas pelo governo. Sendo assim, o decreto de 1890 torna a vigorar até o ano de 1893, deixando de valer a obrigatoriedade de ensino.

Em 1893, foi editada a lei que determinou mais uma reforma da educação do Maranhão, por meio do Decreto n. ${ }^{\circ} 56$, de 15 de maio. Esta lei foi executada por meio de dois regulamentos, sendo o primeiro denominado Regulamento da Instrução Pública do Maranhão, publicado na imprensa no mês de janeiro de 1895, e o outro, denominado de Regulamento Geral da Instrução Pública, de 8 de fevereiro de 1896.

No primeiro Regulamento, não há menção à obrigatoriedade escolar, destacando entre as crianças que padecem de moléstias contagiosas, os menores de seis anos de

8 Benjamin Constant foi engenheiro do Exército e professor da Matemática da Escola Militar, do Instituto de Cegos e da Escola Normal. Foi militar e político e um importante protagonista da derrubada da Monarquia e da formação do primeiro governo republicano. Foi professor e depois diretor do Instituto dos Meninos Cegos, do Rio de Janeiro, durante 20 anos. Foi responsável pela pasta da Instrução Pública, Correios e Telégrafos (CUNHA, 2017). 
idade e os expulsos de outros estabelecimentos públicos como o que deveriam ficar fora do direito à matrícula (REGULAMENTO [...], 1895, art. 33). Quanto à obrigatoriedade de frequência, estão descritas no documento as penalidades para alunos infrequentes sem justificativa dos responsáveis (REGULAMENTO [...], 1895, arts. 38-40). De acordo com esse Regulamento, o ensino em todos os seus graus será livre, e o primário, gratuito (REGULAMENTO [...], 1895, art. . $^{\circ}$ ).

Será o Regulamento Geral da Instrução Pública, de 8 de fevereiro de 1896, elaborado para execução das Leis n. ${ }^{\circ} 56$, de 15 de maio de 1893, e n. ${ }^{\circ} 119$, de 2 de maio de 1895 , que retoma a ideia de compulsoriedade do ensino primário, ao definir que: "O ensino é livre em todos os seus graus, sendo o primário gratuito e obrigatório, nos termos do artigo 6 da lei 119 de 2 de maio de 1895" (REGULAMENTO [...], 1896, p. 1).

A Lei n. ${ }^{\circ} 119$, de 1895, trata-se da reforma de Benedito Leite. ${ }^{9}$ No artigo $6 .^{\circ}$, fica determinada a obrigatoriedade da instrução primária no Estado do Maranhão, a qual pode ser ministrada na casa dos familiares das crianças, nas escolas particulares, nas municipais e nas estaduais (MARANHÃO, 1896). A Reforma Benedito Leite foi editada com o objetivo de reorganizar a educação pública, mas só se reportava ao ensino primário e ao ensino normal. Ela realizava acréscimos na lei de 1893, não tendo objetivo de retrocedê-la. Em seu artigo $7 .^{\circ}$ estabelecia que:

\footnotetext{
Todo o menor de oito a doze anos que residir nas cidades, vilas ou povoações, onde houver escolas públicas do Estado, será obrigatório a frequentá-la, salvo si:

Estiver sendo lecionado na casa da família do menor, tutor ou protetor ou estabelecimento em que trabalha;

For aluno de alguma escola ou estabelecimento particular ou de escola municipal. Parágrafo único: não será obrigatório a frequentar a escola do Estado, nem tão pouco a municipal ou a particular, o menor que tiver incapacidade física ou mental, sofrer de moléstia contagiosa, ou for tão indigente que não tenha meios de preparar-se para frequentar as aulas ainda pelo modo mais modesto (MARANHÃO, 1896, p. 40 , grifo nosso).
}

O mesmo texto acima foi descrito no Regulamento Geral da Instrução Pública do Maranhão, de 1896, em seu artigo 8. $^{\circ}$, o que nos leva a concluir que a obrigatoriedade escolar estabelecida nas reformas da instrução pública maranhenses, do início da República, não se alinhava com a concepção de universalização da educação, considerando que estiveram excluídas da compulsoriedade as crianças doentes, deficientes e os pobres sem condições de se apresentarem com as vestimentas adequadas. Com redações diferentes, e em épocas anterior e posterior ao final do século XIX, as crianças muito pobres são referenciadas como objeto da exclusão escolar na documentação que regulamenta a instrução pública.

9 Benedito Leite foi um dos principais reformadores da educação primária do Maranhão no início da República, conhecido pelo domínio da política do Estado por 15 anos, como líder do partido Federalista. 


\section{DISPENSA DA OBRIGATORIEDADE ESCOLAR DE CRIANÇAS DESPROVIDAS DO VESTUÁRIO “INDISPENSÁVEL A DECÊNCIA E HIGIENE” NAS PRIMEIRAS DÉCADAS DO SÉCULO XX}

Em 1914, por meio da Lei n. ${ }^{\circ} 666$, de 28 de abril, reforma-se a Instrução pública do Estado, definindo que o ensino público do Estado será leigo e gratuito (MARANHÃO, 1914). Nesta reforma, não aparecem dispositivos impeditivos à matrícula, o que será retomado em 1918 por meio do Decreto de 55, de 4 de fevereiro, o qual estabeleceu como condição para efetivação de matrícula, apresentação de prova de vacina e de não sofrer de moléstia contagiosa (alínea b, do art. $6 .^{\circ}$, parágrafo $1 .^{\circ}$, Decreto $n .^{\circ} 55$, de 4 de fevereiro de 1818 , p. 166).

Em 1919, novo decreto, de n. 205 de 12 de julho, baixa o regulamento para o ensino primário, o qual não apresenta nenhum impedimento à matrícula. (REGULAMENTO [...], 1919). Em 1923, publica-se mais um regulamento da instrução pública no Maranhão no qual volta-se a registrar o caráter gratuito e obrigatório do ensino primário, definindo-se critérios para isenção da obrigatoriedade, no qual se inclui não só os pobres em situação de indigência, mas também deficientes, acometidos de doenças contagiosas e as crianças com residência fora do raio de $2 \mathrm{~km}$ da escola pública da região, conforme transcrito:

\footnotetext{
Art. $6 .^{\circ}$ - é gratuito e obrigatório o ensino primário do estado, cumpridas as prescrições da lei $n^{\circ} 119$ de 2 de maio de 1895, com as seguintes modificações.

Ficam isentas as crianças da obrigatoriedade estabelecida:

quando não houver escola pública numa área de $2 \mathrm{~km}$ de raio, ou não houver espaço nas escolas que existirem dentro desta área;

por sofrerem de incapacidade física ou mental, moléstia contagiosa ou repulsiva, por indigência, enquanto se lhes não fornecer o vestuário indispensável à decência e à higiene; se receber instrução primária em casa, ou colégio particular (REGULAMENTO [...], 1923, p. 1, grifo nosso).
}

Observa-se, então, que um novo elemento entra em cena no rol dos critérios de isenção da obrigatoriedade escolar que já vinham se mantendo desde o século XIX, o qual trata-se do item relativo à distância da residência dos alunos em relação à escola, o que não poderia ultrapassar 2 quilômetros.

Em 1931, por meio do Decreto n. ${ }^{\circ} 46$, de 23 de fevereiro, no governo do interventor padre Astolfo Serra, ${ }^{10}$ foi aprovado novo regulamento para instrução pública maranhense. Em nenhuma parte do documento fica registrada a obrigatoriedade escolar, embora se afirme que a frequência era obrigatória, como também o uso do uniforme (REGULAMENTO

10 Astolfo de Barros Serra foi padre, jornalista e poeta, nascido no interior do Maranhão (Vila de Matinha), em 22 de maio de 1900. Foi ordenado padre em 1925, e participou da Coluna Prestes, militou na Aliança Liberal e participou da Revolução de 1930, tornando-se interventor federal no Maranhão pelo Governo de Getúlio Vargas, no período de 9 de janeiro a 18 de agosto de 1931. Escreveu em vários periódicos maranhenses. Faleceu no Rio de Janeiro no dia 19 de fevereiro de 1978 (Cf. MEIRELES, 2001). 
[...], 1931, arts. 116; 124). A única obstrução colocada em relação à matrícula foi quanto ao impedimento de crianças não vacinadas contra varíola, e acometidas de doenças contagiosas (REGULAMENTO [...], 1931, art. 159). Quanto às crianças pobres, aparecem discriminadas no título que trata do fundo escolar. Determina-se que no orçamento da instrução pública se reservará nunca inferior a 50 contos anuais para o fundo de assistência escolar, o qual deveria ter por finalidade:

1. aquisição de livros para alunos pobres;

2. presta-lhes assistência médica e dentária;

3. organizar colônia de férias para alunos pobres;

4. criar escolas onde se aceitem apenas alunos de classe humilde;

5. todas as obras possíveis de assistência escolar;

6. construção de prédios para escolas [...] em bairros pobres e nos lugares do interior (REGULAMENTO [...], 1931, p.12).

Embora não esteja explícita a proibição de matrícula para crianças de baixa condição econômica, no texto do documento, fica patente que a escola pública regida pelo Regulamento de 1931 não se constituía como uma instituição voltada para escolarização das massas de forma universal, já que as crianças pobres são destacadas como objeto de assistência, ou seja, como a exceção. $O$ fato de que os 50 contos anuais para o fundo de assistência escolar devessem ser destinados à criação de escolas especificamente para estudantes pobres, demonstra que estas crianças não representavam o foco da escola pública comum, parecendo-lhes viável a segregação ${ }^{11}$.

Em 1932, no Decreto-Lei n. ${ }^{\circ}$ 252, de 2 de março, outro Regulamento substitui o de 1931. No presente documento, apesar de descrito no art. $2 .{ }^{\circ}$ que a escola "será [...] de tipo único, leiga, aberta a todas as crianças [...] sem distinção de classes..." (REGULAMENTO [...], 1932), observa-se que há um retorno, mais uma vez, ao registro de critérios para a obrigatoriedade escolar, repetindo-se o mesmo conteúdo do regulamento de 1923.

Ratifica-se a exclusão escolar quando são reforçados os critérios de isenção da obrigatoriedade para as crianças que moram até $2 \mathrm{~km}$ das escolas, aos doentes (moléstias contagiosas, repulsivas, incapacidade física ou mental) e para as crianças indigentes, "enquanto se thes não fornecer vestuário indispensável à decência e a higiene" (REGULAMENTO..., 1932, art. 14, p. 2). Observa-se, desta forma, que ainda no início da terceira década do século $\mathrm{XX}$, embora a obrigatoriedade escolar permanecesse nos textos regu-

11 Em 1938 e 1939 foram criadas escolas específicas para crianças pobres no Maranhão, denominadas "escolas dos pés descalços". Eram escolas que funcionavam no modelo isolado, aceitando tanto alunos do sexo masculino quanto feminino (mistas), especialmente voltadas para o atendimento daqueles que não possuíssem nem as vestimentas, nem os calçados adequados para frequentarem as aulas. A criação de espaços específicos onde estas crianças se apresentassem do jeito que podiam, até descalças, funcionava como a solução para incorporar alunos que não possuíam o vestuário considerado adequado, e por isso estavam fora da obrigatoriedade escolar estabelecida nos documentos que regulamentavam a escola primária maranhense (Cf. CRUZ, 2018; 2019b). 
lamentares do ensino público, paralelamente vigoravam, também, restrições à frequência compulsória, com destaque para a exclusão do direito à matrícula, aos pequenos pobres sem condições de vestirem-se conforme a exigência da época. Aspecto estampado em 1933, no Notícias de 9 de maio, como um dos problemas da educação no Maranhão. Para o articulista do jornal:

[...] Impõem-se a obrigatoriedade do ensino em todo o país. Sem esta medida jamais desaparecerá o analfabetismo do Brasil. Aqui, em nosso Estado, o que se observa é a decadência da educação popular. O departamento da Instrução Pública determinou ao ano passado o fechamento de alguns grupos escolares nesta cidade. E sabem o motivo desta medida que a todos encheu de consternação? Segundo nos informam, foi a falta de frequência nesses grupos escolares. Notem bem: não foi a falta de matrícula. Isto quer dizer que os pais não puderam preparar os filhos para frequentar a escola! Não Ihes puderam dar o necessário_ roupa, calçados, livros e cadernos!

Só a obrigatoriedade do ensino resolverá este problema que tem sido adiado em o nosso Estado, sendo um dos inadiáveis.

Que o governo tome conta das crianças pobres e desprotegidas, que existem em todo o Estado, e o Maranhão começará então a respirar pelos próprios pulmões (AINDA [...], 1933, p.1).

Embora houvesse o registro do dispositivo de compulsoriedade do ensino, pela mensagem da matéria pode-se concluir que estava oficializado o abandono da criança pobre pelos poderes públicos, preferindo-se fechar escolas a flexibilizar as exigências incompatíveis com a realidade de pobreza do Estado. Em outra matéria, publicada no jornal Pacotilha de 22 de janeiro de 1938, fica patente que ainda vigora no final da década de 30 uma relação excludente que relacionava riqueza ao direito de escolarização, conforme transcrito abaixo:

Bem sabemos que é muito inferior o "standard" de vida das nossas populações proletárias, em que a falta de meios pecuniários não permite o preparo conveniente das crianças para a frequência de escolas onde se exige a etiqueta, os sapatos envernizados ou as fardas "à dernier cri".

Não se compreende, todavia que, por tais circunstâncias imperativas, as populações infantis pobres dos nossos subúrbios e interiores abandonados fiquem analfabetas simplesmente porque não tiveram a ventura de nascer ricos (PACOTILHA, 1938, p.1).

O articulista do jornal maranhense demonstra que, ao final da terceira década do século $X X$, ainda permaneciam as exigências estabelecidas no século anterior de que as crianças estivessem vestidas e calçadas dentro de um padrão econômico que a grande maioria delas estava impossibilitada pela falta de dinheiro. O culto a boa aparência esta- 
va colocado acima de valores pedagógicos estabelecidos desde a modernidade, os quais agregam à escola, além da função de disseminar o saber, a função de equalização social.

\section{CONSIDERAÇÕES FINAIS}

Neste estudo, pode-se constatar que a escola primária, embora defendida como elemento de democratização da sociedade, pela possibilidade de romper com hierarquização social, ao instituir a meritocracia como consequência da ampliação de oportunidades escolares, foi se configurando como instrumento de reforço de diferenciação e desigualdade social.

Mecanismos como isenção da obrigatoriedade escolar aos desprovidos do vestuário exigido para acessar a escola, diferenciação curricular, estabelecendo conteúdos mais rudimentares para as crianças de localidades mais pobres, ou criação de escolas específicas para os mais pobres demonstram que a oportunidade educacional ofertada pelo poder público no período estudado, sempre se assentou na dualidade.

Pode-se afirmar, então, que a difusão do ensino primária teve como marca um profundo controle das oportunidades educacionais, o qual vem se articulando desde a segunda metade do século XIX no Maranhão, quando o estado passou a contar com uma legislação mais abrangente e minuciosa sobre a educação primária, até os anos seguintes da República, de forma cada vez mais acentuada. Observa-se, ao longo da segunda metade do século XIX e no decorrer das primeiras três décadas do século $X X$, que vigorava um padrão de aluno ideal para a escola pública que consagrava a ideia de escola como espaço fechado para as crianças pobres e deficientes, o que se afirmava pela permanência de mecanismos que legalizavam a exclusão escolar.

Observa-se, desse modo, que apesar dos indiscutíveis avanços ocorridos desde a primeira metade do século XX, com o aumento da escolarização, com a expansão e a federalização do sistema brasileiro, há que se atentar para um fenômeno recorrente em nossa história, o qual consiste no problema da democratização do acesso, tendo em vista que o sistema nacional de educação se expandiu com ênfase na dualidade, contrariando o princípio de universalização.

Sendo assim, pode-se concluir que a permanência de um sistema de ensino dualista tem favorecido a reprodução das desigualdades sociais, uma vez que a escolarização desigual oferecida distintamente conforme a classe social tem como consequência a permanência da pobreza entre os menos escolarizados. 


\section{REFERÊNCIAS}

AINDA. Educação popular. Notícias, São Luís, n. 107, 9 maio 1933.

ARANHA, M. L. A. História da educação e da pedagogia: geral e Brasil. São Paulo: Moderna, 2012.

BRITO, G. M.; VINAGRE, S. Discussões sobre a implantação da obrigatoriedade da educação escolar na Bahia nos jornais O Correio da Bahia e O Monitor de 1876 a 1881. Revista Brasileira de História da Educação. v. 18, Maringá, 2018. Disponível em: http://www.scielo.br/pdf/rbhe/v18/ 2238-0094-rbhe-18-e029.pdf. Acesso em: 22 fev. 2019.

CASTRO, C. A. Os percursos da obrigatoriedade escolar no Maranhão. In: VIDAL, D. G.; SÁ, E. F. de; SILVA, V. L. G. da. (orgs.). Obrigatoriedade escolar no Brasil. Cuiabá, MT: EDUFMT, 2013. p. $11-20$.

CHERVEL, A. História das disciplinas escolares: reflexões sobre um campo de pesquisa. Teoria \& Educação, n. 2. Porto Alegre: Pannonicavol, 1990.

COMENIUS, J. A. S. Didática magna. 2 ed. São Paulo: Martins Fontes, 2002.

CONSTITUIÇÃO política do império do Brasil (de 25 de março de 1824). Presidência da República. Subchefia para assuntos jurídicos. Disponível em: http://www.planalto.gov.br/ccivil_03/Constituicao/ Constituicao24.htm. Acesso em: 22 fev. 2019

CRUZ, Mariléia dos Santos. Obrigatoriedade, homogeneização e tardia expansão da escola primária no interior maranhense (1930 a 1960). In: FURTADO, A. C; SCHELBAUER, A. R.; CORRÊA, R. L. T. (orgs.). Itinerários e singularidades da institucionalização e expansão da escola primária no Brasil. Maringá: EDUEM, 2019a, p.219-242.

"Escola dos pés descalços" como modelo de difusão do ensino primário no Maranhão no período do estado novo. In: Políticas educacionais na educação básica: impactos e perspectivas para escolas públicas. São Luís: EDUFMA, 2019b, v. único, p. 79-95.

Nascimento Moraes e seu pensamento educacional inclusivo com as escolas para crianças pobres. Outros Tempos (Online). v.15, p.1 - 23, 2018.

CUNHA, L. A. A educação brasileira na primeira onda laica: do império à república. Rio de Janeiro: Edição do Autor, 2017.

DIÁRIO DO MARANHÃO, n. 1226, São Luís, 28 out. 1877.

EBY, F. História da educação moderna. Porto Alegre: Globo, 1970

GOVERNO da província: expediente do dia 7 de junho de 1877, Publicador Maranhense, n. 134, p. 1,11 jun. 1877.

GOVERNO do Estado. Decreto n. ${ }^{\circ}$ 94, de 1 de setembro de 1891. Reorganiza a instrução pública. Diário do Maranhão, São Luís, 3 set., 1891. 
GONDRA, J. G. A emergência da escola. São Paulo: Cortez, 2018.

MARANHÃO, Estado do. Lei n 666, de 28 de abril de 1914. Reforma a instrução pública do Estado. Coleção de leis e decretos do Governo do Estado do Maranhão. São Luís: [Imprensa Oficial], 1914.

MARANHÃO, Estado do. Decreto $n^{\circ} 55$, de 2 de fevereiro de 1918. Expede regulamento para as escolas primárias do Estado. Coleção de leis e decretos do Governo do Estado do Maranhão. São Luís: [Imprensa Oficial], 1918.

MARANHÃO, Estado do. Lei Provincial n 115 de 1 de setembro de 1841. A prova o estatuto do Liceu e outras providências acerca do ensino público. Coleção de Leis, decretos e Resoluções da Província do Maranhão- 1835 a 1843. São Luís, Typografia J. A. G. de Magalhães, 1843.

MARANHÃO, Estado do. Lei n 267, de 17 de dezembro de 1849. Reorganiza a instrução pública desta província. In: Coleção de leis, decretos e resoluções da Província do Maranhão. São Luís: Tipografia Constitucional de I. J., 1849.

MARANHÃO, Estado do. Decreto $n^{\circ} 21$, de 15 de abril de 1890. Reorganização do ensino público do Estado. Coleção de decretos leis e resoluções do Governo do Estado do Maranhão. São Luís: Tipografia do Frias, 1893.

MARANHÃO, Estado do. Lei no 119, de 2 de maio de 1895. Reorganiza a Instrução Pública. Coleção de decretos leis e resoluções do Governo do Estado do Maranhão. São Luís: Tipografia do Frias, 1896.

MARANHÃO, Estado do. Regulamento para o Ensino Primário do Estado do Maranhão de 1932, Decreto n. ${ }^{\circ}$ 252, de 2 março de 1932. Diário Oficial do Estado do Maranhão. São Luís: Imprensa Oficial, 1932.

MARANHÃO, Província. Relatório com que o exmo. Sr. Dr. Augusto Olympico Gomes de Castro passou a administração da província ao vice-presidente o exmo. desembargador José Pereira da Graça. São Luís, 29 abr. de 1872.

MARQUES, A. César. Dicionário histórico geográfico da província do Maranhão. Edição fac-similar. Rio de Janeiro: Fon-fon e Seleta, 1970.

MARQUES, A. César. Dicionário histórico geográfico da província do Maranhão. São Luiz: Edições AML, 2008.

MEIRELES, M. M. História do Maranhão. 3 ed. São Paulo: Siciliano, 2001.

O MANIFESTO dos Pioneiros da Educação Nova (1932): a reconstrução educacional no Brasil - ao povo e ao governo. Revista HISTEDBR On-line, 1932. Disponível em: http://www.histedbr.fe.unicamp.br/revista/edicoes/22e/doc1_22e.pdf. Acesso em: 02 AGOS 2019.

PACOTILHA, n. 1030, São Luís, 22 de jan. 1938, p. 1. 
RECENSEAMENTO do Brazil em 1872-Maranhão. Rio de Janeiro: Typografia de G. Leuzinger e Filhos, [1874a] Disponível em https://biblioteca.ibge.gov.br/visualizacao/livros/liv25477_6_br.pdf. Acesso em: 02 ago., 2019.

RECENSEAMENTO do Brazil em 1872. Rio de Janeiro: Typografia de G. Leuzinger e Filhos, [1874b]. Disponível emhttps://biblioteca.ibge.gov.br/visualizacao/livros/liv25477_v1_br.pdf. Acesso em: 02 ago., 2019.

PUBLICADOR MARANHENSE, São Luís, 14 jan., 1870.

PUBLICADOR MARANHENSE, São Luís, n 125, 1877.

RELATÓRIO da instrução pública. Publicador Maranhense, São Luís, n. 99, 1 maio. 1861.

REGIMENTO para as escolas públicas de primeiras letras da província, 16 de junho de 1877. In: CASTRO, A. C. Coleção de Leis e regulamentos da Instrução Pública no Maranhão Provincial. São Luís: EDUFMA, 2009.

REGULAMENTO da casa dos educandos artífices, 2 de dezembro de 1841. In: CASTRO, A. C. Coleção de Leis e regulamentos da Instrução Pública no Maranhão Provincial. São Luís: EDUFMA, 2009a.

REGULAMENTO da casa dos educandos artífices, 7 de março de 1855. In: CASTRO, A. C. Coleção de Leis e regulamentos da Instrução Pública no Maranhão Provincial. São Luís: EDUFMA, 2009b.

REGULAMENTO da Instrução Pública, de 2 de fevereiro de 1855. Reorganiza e regula o ensino elementar e secundário. In: CASTRO, A. C. Coleção de Leis e regulamentos da Instrução Pública no Maranhão Provincial. São Luís: EDUFMA, 2009c.

REGULAMENTO do asilo de Santa Teresa, 16 de janeiro de 1855. In: CASTRO, A. C. Coleção de Leis e regulamentos da Instrução Pública no Maranhão Provincial. São Luís: EDUFMA, 2009d.

REGULAMENTO da Instrução Pública de 17 de julho de 1874, lei número 1091. Aprova o regulamento da instrução pública. In: CASTRO, A. C. Coleção de Leis e regulamentos da Instrução Pública no Maranhão Provincial. São Luís: EDUFMA, $2009 e$.

REGULAMENTO da instrução pública do Maranhão: para execução da lei $n^{\circ} 56$, de 15 de maio de 1893. Diário do Maranhão. São Luís, 12 jan., 1895.

REGULAMENTO geral da instrução pública do Maranhão: para execução das leis $n^{\circ} 56$, de 15 de maio de 1893 e lei 119 de 2 de maio de 1895. Diário do Maranhão. São Luís, 26 mar., 1896.

REGULAMENTO a que se refere o decreto $n^{\circ}$ 616, de 15 de fevereiro de 1923. Diário Oficial do Estado do Maranhão. São Luís, 29 fev., 1923.

REGULAMENTO para o ensino primário. Decreto $n^{\circ} 206$ de 12 de julho de 1919. Diário Oficial do Estado do Maranhão. São Luís, 16 jul., 1919. 
SILVA, Alexandre Ribeiro e. "Este interessante ramo do serviço público": produção de reformas da instrução pública no Maranhão Imperial (1838-1864). 2018. 331 f. Dissertação (Mestrado - Programa de Pós-Graduação em Educação. Área de Concentração: Cultura, Filosofia e História da Educação) - Faculdade de Educação da Universidade de São Paulo, São Paulo, SP.

VEIGA, C. G. "Promiscuidade de cores e classes": tensões decorrentes da presença de crianças negras na história da escola pública brasileira. In: BARROS, S. A. P.; FONSECA, M. V. A história da educação dos negros no Brasil. Niterói: EDUFF, 2016.

VIDAL, D. G. Faces da obrigatoriedade escolar: lições do passado, desafios do presente. In: VIDAL, D. G.; SÁ, E. F. de; SILVA, V. L. G. da (orgs.). Obrigatoriedade escolar no Brasil. Cuiabá, MT: EDUFMT, 2013. p. 11-20.

VIVEIROS, Jerônimo de. Apontamentos para a história da instrução pública e particular do Maranhão. Revista de Geografia e História, São Luís, ano IV, dez. 1953. 